\title{
A PRÁTICA EDUCATIVA AMBIENTAL DE PROFESSORES PEDAGOGOS COM SEUS ALUNOS A PARTIR DO CONTO “A MAIOR FLOR DO MUNDO” DE JOSÉ SARAMAGO
}

\author{
Marcela de Moraes Agudo ${ }^{1}$ \\ Marília Freitas de Campos Tozoni-Reis ${ }^{2}$
}

RESUMO

Este trabalho teve por objetivo apresentar e analisar as práticas educativas ambientais que professores pedagogos das duas escolas participantes da pesquisa realizaram com seus alunos a partir do conto infantil "A maior flor do mundo" de José Saramago e os sentidos que os professores encontraram no livro. O estudo utilizou os pressupostos da pesquisa qualitativa em educação, em que os pesquisadores estudam a realidade no seu contexto, tal e como acontece. A modalidade que inspirou o seu desenvolvimento foi a pesquisa-ação para o trabalho com professores pedagogos que lecionam anos iniciais do Ensino Fundamental de duas escolas públicas estaduais do Estado de São Paulo. Tendo como referência o recorte estabelecido pelo objetivo deste artigo, são apresentadas e analisadas as atividades que os professores desenvolveram com seus alunos. A perspectiva que foi levada aos professores no processo de pesquisa foi da educação ambiental crítica, que traz as origens e causas reais e concretas das questões socioambientais. Contudo, os professores apresentaram uma concepção romantizada e naturalizante da relação natureza e sociedade. Com isso, considera-se necessário compreender a relação entre ser humano, sociedade e natureza pela abordagem crítica, problematizadora e histórica.

PALAVRAS-CHAVE: Educação ambiental. Pedagogia. Formação de professores.

\section{THE ENVIRONMENTAL EDUCATION PRACTICE OF PEDAGOGUE TEACHERS WITH THEIR STUDENTS WITH THE HISTORY "THE BIGGEST FLOWER IN THE WORLD" BY JOSÉ SARAMAGO}

\begin{abstract}
This work aims at presenting and analyzing the environmental educational practices that pedagogue teachers of research participating schools conducted with students from the children's tale "The largest flower in the world" by José Saramago and the significations that teachers found in the book. The study used the assumptions of qualitative research in education, that researchers study the reality in context, as it happens. The modality that inspired its development was action-research to the work with teachers who teach to early years of elementary education in two public schools in the State of São Paulo. With reference to the profile set by purpose of this article, the activities that teachers have developed with their students are presented and analyzed. The aspect that was taken to teachers in the research process was the critical environmental education, which brings up the origins and real causes of social and environmental issues. However, teachers showed a romanticized and
\end{abstract}

\footnotetext{
${ }^{1}$ Mestre e doutoranda em Educação para a Ciência, UNESP/Bauru. marcelamagudo@gmail.com

${ }^{2}$ Professora Adjunta, UNESP/Botucatu. mariliaedu@ibb.unesp.br
} 


\section{LA PRÁCTICA AMBIENTAL DE PROFESORES PEDAGOGOS CON SUS ALUMNOS DESDE EL CUENTO "LA FLOR MÁS GRANDE DEL MUNDO" DE JOSÉ SARAMAGO}

\section{RESUMEN}

Este trabajo tiene como objetivo presentar y analizar las prácticas de educación ambiental que los profesores pedagogos de ambas escuelas participantes en el estudio realizado con estudiantes de cuento infantil "La flor más grande del mundo", de José Saramago y los sentidos que los profesores encuentran en el libro. El estudio utilizó los supuestos de la investigación cualitativa en la educación, donde los investigadores estudian la realidad en su contexto, como sucede. La modalidad que inspiró su desarrollo fue la investigación-acción para trabajar con los maestros educadores que enseñan primeros años de la educación primaria en dos escuelas públicas en el Estado de São Paulo. Con la referencia el corte establecido por el propósito de este artículo, se presentan y analizan las actividades que los profesores han desarrollado con sus alumnos. La perspectiva que fue llevado a los profesores en el proceso de investigación fue la educación ambiental crítica que lleva a los orígenes y las reales causas de los problemas socioambientales. Sin embargo, los profesores presentan una concepción romántica y naturalista de la relación entre la naturaleza y la sociedad. Por lo tanto, se considera necesario entender la relación entre ser humano, la sociedad y la naturaleza por el enfoque crítico, problematizador y histórico.

PALABRAS-CLAVE: Educación ambiental. Pedagogía. Formación de profesores.

\section{INTRODUÇÃO}

A discussão apresentada neste estudo deriva de uma investigação em nível de mestrado cujo objeto teve como foco a formação de pedagogos na educação infantil. Este trabalho tem por finalidade estudar a apropriação de educação ambiental dos professores, os sentidos que eles encontraram no livro infantil "A maior flor do mundo" de José Saramago, e o trabalho do conto infantil com seus alunos dos anos iniciais do Ensino Fundamental de duas escolas públicas estaduais de uma cidade do Estado de São Paulo.

O estudo utilizou os pressupostos da pesquisa qualitativa em educação, em que os pesquisadores estudam a realidade no seu contexto, tal e como acontece. Para tanto, a modalidade que inspirou o seu desenvolvimento foi a pesquisa-ação (BARBIER, 2004), a qual estabeleceu três pontos essenciais: que os pesquisadores técnicos - os docentes de uma escola - percebam o processo educativo como um objeto passível de pesquisa; que estes pesquisadores percebam a natureza social e 
as consequências da reforma em curso; e que compreendam a pesquisa como uma atividade social e política.

Os pressupostos teóricos se basearam nos princípios da educação ambiental crítica (TOZONI-REIS, 2005), que visa a possibilidade de transformação da realidade como possibilidade de superação da problemática ambiental, em uma perspectiva democrática, para a prática de uma educação facilitadora da transformação social, proporcionando a formação de conhecimentos que promovam o desenvolvimento do sujeito nas relações da sociedade com o ambiente - natural e social - em que ele vive (LOUREIRO et al., 2012). Além desta perspectiva crítica da educação ambiental, o estudo também destacou a educação ambiental escolar como principal tema a ser estudado.

No processo formativo com os professores foram trabalhadas as diferentes concepções de educação ambiental, elaboradas por Sauvé (2005), debatendo suas diferenças e complementaridades ${ }^{3}$. Foi estudado junto aos professores o texto de Tozoni-Reis (2008), em que três perspectivas pedagógicas de educação ambiental são discutidas: comportamentalista; conteudista; e transformadora.

Para o artigo que ora se apresenta, estabeleceu-se como objetivo apresentar e analisar as práticas educativas ambientais que os professores pedagogos das duas escolas participantes da pesquisa realizaram com seus alunos durante o desenvolvimento da investigação.

Tendo como referência o recorte estabelecido, a discussão apresentada aborda as análises dos resultados frutos dos relatos orais de reuniões com os professores e dos relatos de experiência que os professores escreveram ao final das atividades, em que fazem um balanço das atividades que desenvolveram com seus alunos e suas impressões e percepções sobre as possibilidades de desenvolvimento da educação ambiental no cotidiano de sua prática pedagógica.

\footnotetext{
${ }^{3}$ As categorias formuladas por Sauvé (2005) foram trabalhadas para enfatizar a diversidade de propostas teórico-metodológicas no âmbito da educação ambiental também para um posicionamento diante delas. Esta autora destaca, entre as abordagens mais recentes em educação ambiental, as seguintes "correntes": holística; biorregionalista, práxica, crítica, feminista, etnográfica, da ecoeducação e da sustentabilidade.
} 
Para a organização do texto, optou-se por apresentar os resultados que emergiram das atividades desenvolvidas nas duas escolas - Escola 1 e Escola 2 - e, em seguida, o processo de análise dos dados com base nos pressupostos teóricos da educação ambiental crítica, conforme se segue.

\section{METODOLOGIA}

Esta pesquisa teve como base a pesquisa qualitativa em educação, considerando a relação dinâmica entre a realidade e o sujeito (MINAYO, 1994) e, principalmente, levantando a pesquisa-ação-participativa como metodologia inspiradora para este estudo. Com isso, foi realizada a investigação junto de professores de duas escolas públicas estaduais que lecionam para o Ensino Fundamental, objetivando a participação desses professores por meio de tomadas de decisões e problematizações coletivas sobre a prática pedagógica em educação ambiental na escola, considerando suas possibilidades e dificuldades.

Uma das ideias principais da pesquisa-ação-participativa, compreendida neste estudo, foi de que a realidade social não é algo dado e acabado, pois os sujeitos fazem parte da história, são definidos por ela, do mesmo modo que a constroem.

Conhecer a sua própria realidade. Participar da produção deste conhecimento e tomar posse dele. Aprender a escrever a sua história de classe. Aprender a reescrever a História através da sua história. Ter no agente que pesquisa uma espécie de gente que serve. Uma gente aliada, armada dos conhecimentos científicos que foram sempre negados ao povo, àqueles para quem a pesquisa participante - onde afinal pesquisadores-e-pesquisados são sujeitos de um mesmo trabalho comum, ainda que com situações e tarefas diferentes - pretende ser um instrumento a mais de reconquista popular (BRANDÃO, 1999, p. 11).

O recorte da pesquisa que constitui este artigo apresenta resultados que tiveram como objetivos elaborar, junto dos professores envolvidos, atividades de reescrita do conto, dos professores com seus alunos, tendo como referência a educação ambiental crítica; e refletir sobre as possibilidades de inserção da educação ambiental crítica na prática pedagógica dos professores pedagogos dos anos iniciais do Ensino Fundamental. 


\section{ATIVIDADES DESENVOLVIDAS NA ESCOLA 1}

Nesta escola os professores desenvolveram diferentes atividades com 0 conto, evidenciadas por meio de seus relatos e das produções dos alunos. Alguns professores desenvolveram atividades que eles próprios formularam, e outros fizeram a reescrita do conto. Foi interessante observar que os professores de Artes, articularam-se com os outros professores neste trabalho.

Uma professora de Artes desenvolveu o trabalho do conto "A maior flor do mundo" com os alunos por meio de um filme de curta metragem. Ela considerou que os alunos não entenderam a história, pois quando ela perguntava o que precisava para a planta se desenvolver, os alunos falavam de água, sol, porém ela gostaria que eles dissessem amor, cuidado, carinho. Ela colocou isso para seus alunos e eles concordaram e aceitaram.

É possível notar em seu relato que ela considerou que os alunos não compreenderam a história da maneira que ela entendeu e gostaria que eles percebessem, que o menino havia salvado a flor por "amor à natureza". No entanto, os desenhos mostram a flor, o menino, as pessoas na aldeia e a montanha bem alta (Figura 1), destacam, inclusive, o cuidado necessário à flor.

\section{Figura 1. Desenho de um aluno da Professora de Artes.}

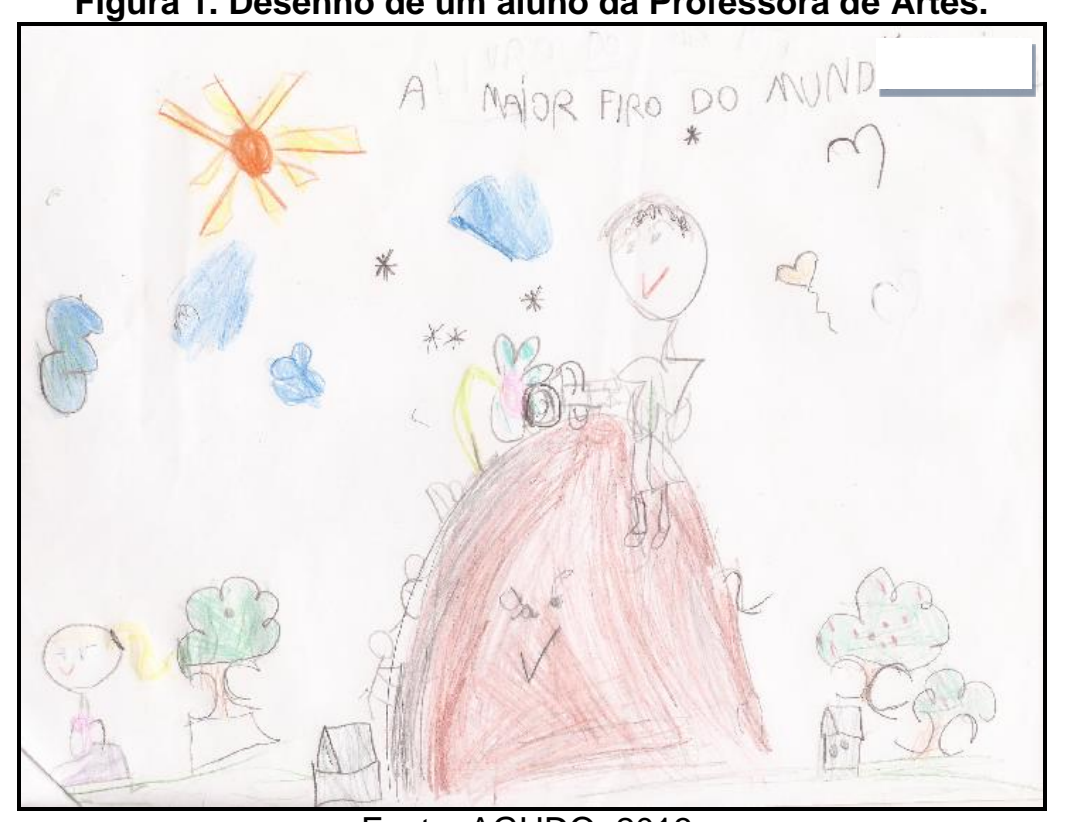

Fonte: AGUDO, 2013. 
O professor de Artes usou o livro, destacando o uso das técnicas que o ilustrador utilizou e reproduzido-as com os alunos. Depois, falou sobre arte contemporânea, discutindo outros conceitos, como o de liberdade, numa roda de conversas com os alunos.

As professoras pedagogas, em geral, iniciaram as atividades com o conto seguindo uma sequência semelhante. Inicialmente, os alunos folhearam os livros, passando a mão e cheirando o livro; depois do livro percorrer entre os alunos, as professoras liam o conto para seus alunos. Depois a professora falava sobre a reescrita e realizavam a reescrita do conto. Os alunos mais novos realizavam a reescrita coletiva, tendo a professora como escriba; e os alunos mais velhos reescreviam contos individualmente.

Para a mesma sala de segundo ano que a professora de Artes trabalhou com o filme, a professora da turma iniciou a reescrita, o que parece ter sido muito interessante, pois os alunos tiveram a oportunidade de dar continuidade à atividade em mais de uma disciplina.

Em relação ao processo educativo ambiental, outra professora discutiu a questão da relação do ser humano com a natureza, pois se o menino aproveitava todo aquele lugar que ele gostava de brincar, também deveria retribuir, e ele retribuiu cuidando da flor. Assim como na experiência da professora de Artes, o tema do "amor pela natureza" esteve presente na experiência de outras professoras.

As professoras ficaram bastante orgulhosas de terem conseguido desenvolver a atividade com o conto "A maior flor do mundo" com seus alunos. A ideia geral dos professores dessa escola foi que cada aluno desenvolvesse um livrinho recontando a história de José Saramago.

Dois professores consideraram que os alunos não entenderam muito bem o conto, mas o trabalho das crianças indica que entenderam, pois conseguiram reescrevê-lo e ilustrá-lo. Uma aluna escreveu que o menino era gentil, outro que o menino estava em outro planeta e que lá ele salvava a natureza. Nas reescritas dos alunos de uma professora, eles incluíram histórias que não estavam no conto de Saramago. Um aluno escreveu que o menino disse para a mãe que iria até a lua, a mãe falou que era muito difícil, porém que se ele conseguisse, ela daria os parabéns. 
Em uma reescrita o aluno narrou que o menino estava entre as árvores e viu uma árvore derrubada com "aquele cheiro de árvore"; outro aluno contou que o menino "sentiu cheiro de caule e vegetais".

No relato de uma professora, observamos a perspectiva da preservação ambiental. Embora alguns professores não tenham conseguido relacionar a história com as questões ambientais, aqui essa relação foi percebida claramente, como preservação:

Desde a $1^{\text {a }}$ leitura alguns aspectos foram mais relevantes ao grupo, como a questão da preservação, em que se compadeceram da flor, mas diziam que usariam outras maneiras para regar a planta.

\section{ATIVIDADES DESENVOLVIDAS NA ESCOLA 2}

Duas professoras revezaram 0 uso dos livros deixados na escola $e$ desenvolveram atividades com seus alunos no final de 2011. A história foi apresentada pelos alunos por meio de um teatro no show de talentos da escola, que apresenta dança, música e teatro das crianças para seus familiares e amigos. Neste dia, um sábado, a escola estava com os portões abertos, muitos pais, avós, irmãos e amigos dos alunos estavam presentes. Nas salas de aula estavam à venda guloseimas e realizavam-se atividades interativas como brincadeiras e pintura com os alunos. No palco, as apresentações aconteciam. Foi apresentado o conto "A maior flor do mundo" escrito coletivamente com os alunos, em forma de teatro. O cenário foi montado e as crianças interpretaram a história (Figura 2). 
Figura 2. Alunas da Escola 2 narram a reescrita coletiva do segundo ano e alunos representam a história.

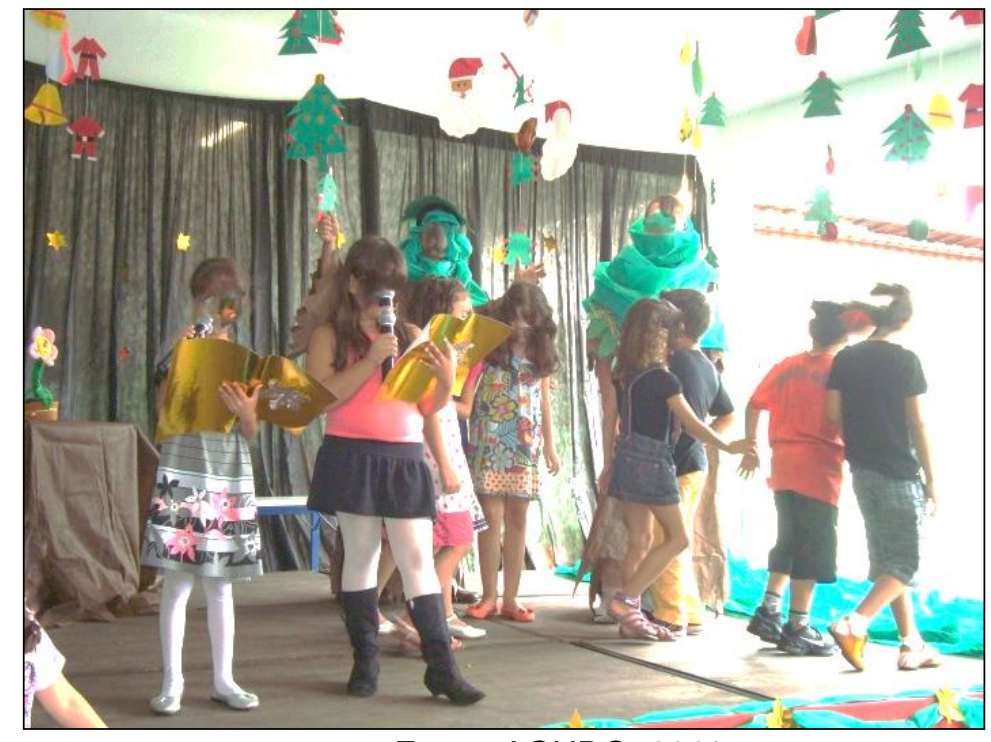

Fonte: AGUDO, 2013.

Neste cenário, duas alunas narravam a história reescrita por todos enquanto outros alunos representavam a história. $\mathrm{Na}$ encenação, cada aluna lia um trecho da narrativa intercaladamente. Enquanto isso, os alunos encenavam. No fim da história, foi narrado que o menino salvou a flor, pois ele havia cuidado dela com amor. Ao final da apresentação, os alunos cantaram uma canção que tematiza a infância, intitulada "Toda criança quer" do grupo "Palavra Cantada":

Toda criança quer

Toda criança quer crescer

Toda criança quer ser um adulto

$E$ todo adulto quer

$E$ todo adulto quer crescer

Para vencer e ter acesso ao mundo

$\mathrm{E}$ todo mundo quer

$E$ todo mundo quer saber

De onde vem
Pra onde vai

Como é que entra

Como é que sai

Por que é que sobe

Por que é que cai

Pois todo mundo quer...

(Péricles Cavalcanti - CD - Pé com pé - Palavra Cantada)

Outras professoras desta escola também trabalharam com o conto infantil. A maior parte das professoras leu a história diversas vezes e seus alunos fizeram desenhos ilustrativos. Por exemplo, em alguns desenhos, os alunos ilustraram o menino colocando água para a flor, em outros a chuva caindo e um jardim recebendo a água da chuva. Nesta atividade realizada por uma professora da Escola 2, o que 
mais chamou a atenção foi o desenho de uma aluna que desenhou o planeta Terra, com pessoas e casas espalhadas em sua superfície (Figura 3).

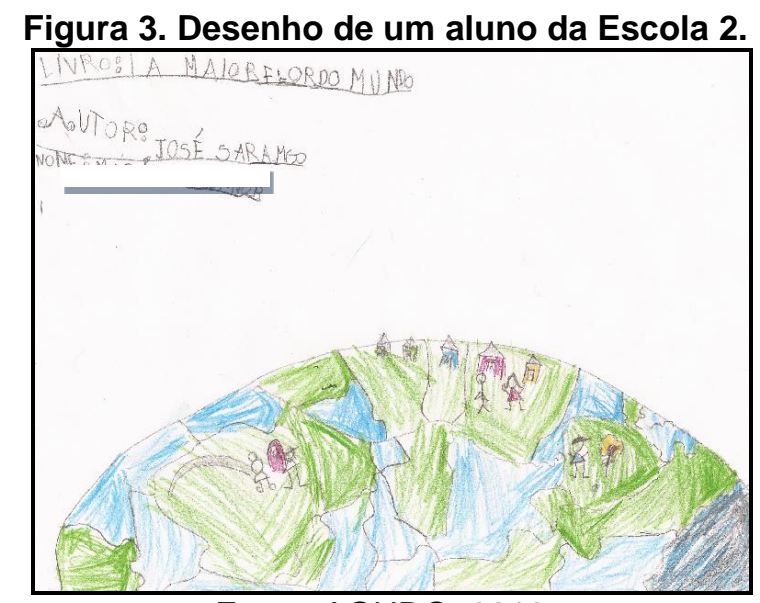

Fonte: AGUDO, 2013.

Nota-se que este desenho vai além da ilustração da história, problematiza as questões ambientais de forma mais geral, o que indica uma percepção da dimensão ambiental da atividade desenvolvida pelos alunos.

Uma professora da Escola 2 desenvolveu, primeiramente, uma atividade questionando seus alunos do segundo ano sobre o que era ecologia. Nesta atividade as crianças responderam a questão em uma tarjeta de papel. A maioria considerou ecologia como "jogar lixo no lixo", "reciclagem", "economia de energia”, "respeitar a natureza" e "cuidar do planeta". Outras crianças consideraram como "bichos", "zoológico" e "pesquisa de animais". Alguns ainda escreveram como "eu penso que é dos científicos" e "pesquisa sobre humano".

No relato desta professora, embora não tenha indicadores diretos de que a discussão ambiental que ela desenvolveu com seus alunos, por meio do livro, aproxime-se da perspectiva de preservação da natureza, tendo em vista "um futuro melhor", na apresentação da história em forma de teatro, as alunas que estavam narrando a história contaram, ao final, que o menino só conseguiu salvar a flor, pois ele fez com amor. Essa confusão entre as diferentes abordagens da educação ambiental explicita-se aqui na valorização que a professora deu ao que os alunos aprenderam: proteger e amar a natureza. 
Além disso, em outra atividade que esta professora desenvolveu com os alunos, foram identificados alguns indicadores dessa concepção, em especial na questão que colocou a eles: "o que você pode fazer para ajudar o planeta Terra?" os alunos responderam a isso por escrita ilustrada, expressando vários comportamentos ambientalmente adequados e inadequados, bastante prescritivos como: "não jogar lixo na rua", "não colocar fogo no mato", "cuidar dos animais", "não cortar as árvores", "não queimar pneus", "pegar carona com um amigo". A reescrita coletiva do conto foi desenvolvida como a última em sala de aula nesse processo.

Figura 4. Detalhe do mural com trabalhos que uma professora da Escola 2 desenvolveu com os alunos do primeiro ano do Ensino Fundamental.

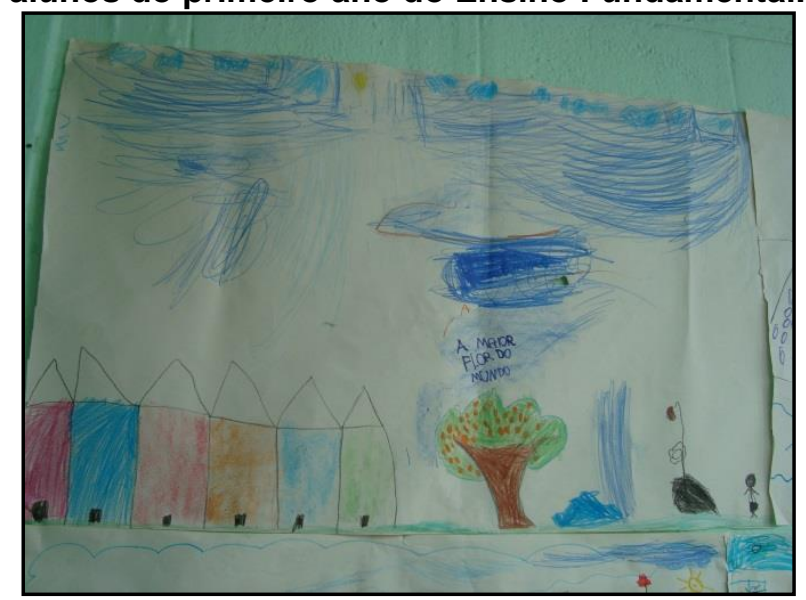

Fonte: AGUDO, 2013.

Outra professora também desenvolveu a atividade com o conto, mas com os alunos do terceiro ano. Ela comentou que alguns alunos que nunca produziam trabalho algum na sala de aula, fizeram a atividade e ela guardou três trabalhos como documentos de produção destes alunos. Esta professora considerou a ação do Homem na natureza, evidenciado em seu relato de experiência:

Iniciei uma conversa com os alunos do $3^{\circ}$ ano $B$ sobre o meio ambiente, falamos sobre ambientes naturais e construídos; e dessa forma puderam perceber um pouco sobre a ação do homem na natureza.

No entanto, a concepção predominante de educação ambiental das professoras está no sentido de uma educação ambiental para a mudança de 
comportamentos ambientalmente inadequados, como pode ser localizado no trecho do relato de experiência de uma professora:

Depois da leitura fizemos uma pausa para falarmos sobre a atitude que fez do menino um menino diferente, na opinião deles. $E$ alguns logo disseram porque ele salvou a flor. Daí partimos para outras atitudes que poderiam ser consideradas positivas como a dele. E surgiram: cuidar dos animais, cuidar dos planetas, não jogar lixo no chão, não sujar os rios. Então questionei sobre o ambiente na escola como poderíamos ajudá-lo. E chegamos a conclusão que depende de cada um cuidar do seu espaço. Como cuidar do mundo se não cuidamos da sala, por exemplo? As pequenas atitudes é que contam.

\section{ANÁLISE DO PROCESSO}

Nas atividades que os professores desenvolveram com seus alunos não houve diferenças significativas entre a Escola 1 e a Escola 2. Algumas pequenas diferenças nas atividades que os professores desenvolveram, seus relatos e as produções dos alunos levam a uma mesma discussão.

Em relação à produção dos alunos, pode-se compreender que eles entenderam a história quando buscaram pelas palavras desconhecidas perguntando aos professores. Interessante notar como isso os motivou e estimulou a reescrita do conto. Eles tiveram grande interesse pelo conto, sempre querendo ouvir a história muitas vezes, solicitando aos professores para desenharem a história.

$\mathrm{Na}$ Escola 1, quando os alunos da professora de Artes eram questionados sobre o que era necessário para que a planta se desenvolvesse, falavam que a planta precisavam de água, sol, chuva; mostrando que eles tinham um conhecimento mais sofisticado, já elaborado sobre as plantas e como elas são diferentes dos seres humanos. Os alunos de uma professora se interessaram bastante pelas ilustrações do livro, embora os professores, de forma geral, não conseguissem perceber da mesma forma.

$\mathrm{Na}$ Escola 2, foi bastante notável o desenho de uma aluna que ilustrava o planeta Terra, com pessoas e casas espalhadas em sua superfície. Este desenho vai 
além da ilustração da história, problematiza as questões ambientais de forma mais geral. Alguns alunos, que nunca produziam trabalho algum na sala de aula, realizaram a reescrita do conto e a professora guardou exemplares como documentos de produção destes alunos.

Esses resultados mostram o interesse e a compreensão do conto pelos alunos. Considerando que o objetivo era partir do conto para inserir a educação ambiental na prática pedagógica dos professores, o ponto de partida produziu resultados importantes com os alunos. No entanto, a continuidade do trabalho com a educação ambiental, depois desta atividade como ponto de partida, dependia dos professores, e não houve dados sobre isso.

Os resultados mostram que em ambas escolas os professores levaram aos alunos a perspectiva de cuidado com a natureza, pensando no futuro, para que o meio ambiente possa existir futuramente.

Os professores da Escola 1, em sua maioria, desenvolveram a proposta da mesma maneira: os alunos desenvolviam livros com a sua versão da história e ilustrações próprias. O professor de Artes, inclusive, adicionou seu trabalho com os alunos na confecção dos livros. Apesar de ser importante o diálogo entre os professores para discutirem o que seria feito, esse aspecto evidenciou o medo que tinham de "errar", com receio de serem avaliados negativamente.

Uma professora mostrou em seu relato que os alunos questionaram bastante em torno da história. Os professores tinham expectativas de que os alunos não se interessariam e nem entenderiam a história e as ilustrações. As atividades de uma professora com seus alunos, antes da reescrita do conto, mostraram uma perspectiva de educação ambiental técnica e conteudista, abordando ecologia e atitudes de preservação ambiental, de forma bastante confusa.

No geral, os professores transitaram em perspectivas preservacionistas de educação ambiental, com ênfase no desenvolvimento sustentável e nos aspectos sensibilizadores de proteção à natureza. Poucos deles conseguiram relacionar o conteúdo do conto com o da educação ambiental..

Enquanto os professores gostariam que os alunos enxergassem a necessidade de proteção e preservação ambiental, além de "cuidar" da natureza, 
inclusive por meio de estímulo às comportamentos adequados, os alunos fizeram questionamentos, demonstrando interesse pela proposta e pelo processo de educação ambiental.

No entanto, para que a educação ambiental possa ser desenvolvida com os alunos na forma de inserção curricular, a mediação dos professores é fundamental. Com a mediação do professor, os alunos podem aprofundar os estudos que se referem à educação ambiental de forma mais crítica, apropriando-se desses conteúdos com mais propriedade e consistência.

Assim, compreende-se que a educação ambiental transformadora, segundo a orientação teórica deste estudo, aquela que possibilita a transformação socioambiental, por meio também do processo de ensino e de aprendizagem, tem sua perspectiva de inserção na escola diretamente relacionada às perspectivas gerais de atuação dos professores na educação básica. Para que os professores pensem a inserção da educação ambiental como um processo de apropriação crítica e reflexiva de conhecimentos, é necessário pensar na possibilidade de aprendizagem mais consistente dos seus alunos, desenvolvendo atividades que garantam que eles se apropriem dos conhecimentos. De acordo com Trein (2012, p. 306-307),

sabemos que a construção de utopias, que impliquem em profundas transformações sociais, é influenciada, permanentemente, por forças externas, que buscam ajustar a realidade em direção à conservação do já existente. Nesse sentido, o peso do passado, do já conhecido, oferece uma "segurança", que muitas vezes arrefecem o ímpeto das ações com potencial transformador.

Os dados indicam que muitos professores têm concepções equivocadas da capacidade de aprender de seus alunos, o que impede práticas pedagógicas comprometidas com a apropriação de conhecimentos em perspectivas transformadoras. Para que os professores tenham acesso aos fundamentos da educação, aos conhecimentos mais elaborados sobre os processos educativos escolares, incluindo as abordagens da educação ambiental crítica, são necessários cursos de formação, para o estudo reflexivo e crítico de sua prática cotidiana. Políticas públicas e programas são formas para que esta formação ocorra, podendo favorecer um novo olhar sobre o meio ambiente. 
Apesar dos programas e políticas públicas serem bastante discutidos nas escolas públicas, a perspectiva de educação ambiental é a mesma, uma educação ambiental técnica, fragmentada e preservacionista. Assim, considera-se que a educação ambiental foi inserida na escola pública de maneira superficial e ainda é desta forma, devido aos contextos locais diferentes e aos programas regulatórios que chegam ao ambiente escolar. Para que uma educação ambiental crítica seja desenvolvida nas escolas é necessário políticas e práticas de formação de professores, considerando o contexto de trabalho dos professores, além de proporcionar a eles autonomia e reflexão crítica sobre a educação ambiental.

Refletindo sobre as possibilidades a partir do conto infantil "A maior flor do mundo" para a inserção da educação ambiental na escola pública, a proposta foi que os professores concebessem o conto e as atividades de leitura e reescrita como ponto de partida para iniciar a reflexão sobre a inserção da educação ambiental na escola. Neste sentido, a perspectiva que foi levada aos professores no processo de pesquisa foi da educação ambiental crítica, que problematiza, traz as origens e causas reais e concretas das questões socioambientais, no sentido de compreender a relação entre ser humano, sociedade e natureza, que é proporcionada pelo trabalho, utilizando a abordagem crítica, problematizadora, histórica e dialética.

\section{CONCLUSÃO}

Um professor com uma concepção naturalizante e romantizada da relação ser humano e natureza ressaltaria, a partir do conto, puramente a natureza estética, a beleza da paisagem naturalizada, revelando a tendência natural, considerando que a educação deve reintegrar o ser humano à natureza, adaptando-o à sociedade (TOZONI-REIS, 2008).

Tendo em vista uma educação ambiental crítica, histórica, poderia ser discutido com os alunos a relação que o ser humano possui com seu ambiente, não na perspectiva naturalizante, mas na perspectiva histórica, em que o meio ambiente não seria somente uma floresta, algo intocado pelo Homem, mas também os ambientes transformados pelo ser humano. Com isso, seria possível discutir os 
resultados que essa ação do homem, por meio de seu trabalho, traz para o meio ambiente e para a sociedade, refletindo com os alunos sobre perspectivas de mudanças.

A história, munida da ilustração, possui um conteúdo estético de muito valor, possibilitando compreensão diversa, pois é carregada de simbolismos e conteúdos artísticos. O artista expressa o conteúdo de sua obra por meio da forma. O leitor, atento para o conteúdo, somente consegue atingi-lo por meio da forma utilizada pelo artista. O artista une forma e conteúdo em sua obra. O leitor, conseguindo ter acesso à forma e ao conteúdo, apropria-se de conteúdos para fazer-se cada vez mais pleno em seu processo de tornar-se humano: "Uma relação que se dirige ao conteúdo da obra, mas é dirigida por sua forma, num processo em que o indivíduo está em contato com a aparência, mas esta o conduz a questões essenciais da história humana." (DUARTE; FERREIRA; ANJOS, 2012, p.4).

Este processo, no entanto, necessita da mediação do professor, para tornar o conteúdo apropriável pelos alunos na escola. Assim, os alunos podem compreender todo o processo da produção do conhecimento e as possibilidades de sua transformação (SAVIANI, 2005).

O professor, na perspectiva crítica da educação ambiental, proporcionaria outro entendimento dos alunos em relação às problemáticas socioambientais. Assim, seria possível que os alunos entendessem que a problemática socioambiental possui múltiplos fatores e que não é natural e nem está estagnada, mas que é passível de mudanças por meio da ação do homem enquanto indivíduo singular e coletivo.

\section{Processo no 2010/14349-7, Fundação de Amparo à Pesquisa do Estado de São Paulo (FAPESP).}

\section{REFERÊNCIAS}

AGUDO, Marcela de Moraes. "A maior flor do mundo" de José Saramago e a educação ambiental na escola. 2013. 201f. Dissertação (Mestrado em Educação para a Ciência). Universidade Estadual Paulista, Bauru, 2013.

BARBIER, Rene. A Pesquisa-Ação. Brasília: Liber Livro Editora, 2004. 159 p. 
DUARTE, Newton; FERREIRA, Nathalia Botura de Paula; ANJOS, Ricardo Eleutério. Trabalho Completo, 2012. O conceito ético-político de catarse e a importância da adolescência para a formação humana. Anais ANPED - Associação Nacional de Pós-Graduação e Pesquisa em Educação. Disponível em: < http://35reuniao.anped.org.br/images/stories/trabalhos/GT17\%20Trabalhos/GT17-1529_int.pdf>. Acesso em: 07 nov. 2012.

LOUREIRO, Carlos Frederico Bernardo; TREIN, Eunice; TOZONI-REIS, Marília Freitas de Campos; NOVICKI, Victor. Contribuições da teoria marxista para a educação ambiental crítica. Cadernos CEDES, Campinas, v. 29, n. 77, p. 81-97, 2012.

MINAYO, Maria Cecília de Souza. Pesquisa social: teoria, método e criatividade. Petrópolis, RJ: Vozes. 1994.

SAUVÉ, Lucie. Uma cartografia das correntes em Educação Ambiental. In: SATO, Michele; CARVALHO, Isabel Cristina Moura. (Orgs.). Educação Ambiental: pesquisa e desafios. Porto Alegre: Artmed, 2005.

SAVIANI, Dermeval. Pedagogia histórico-crítica: primeiras aproximações. 9 ed. Campinas: Autores Associados, 2005.

TOZONI-REIS, Marília Freitas de Campos. Educação ambiental: natureza, razão e história. 2 ed. Campinas, SP: Autores Associados, 2008.

TOZONI-REIS, Marília Freitas de Campos. PESQUISA-AÇÃO: Compartilhando saberes; Pesquisa e Ação educativa ambiental. In: FERRARO JÚNIOR, Luiz Antônio. (Org.) Encontros e caminhos: formação de educadoras(es) ambientais e coletivos educadores, Brasília: Ministério do Meio Ambiente, 2005. p. 269-276.

TOZONI-REIS, Marília Freitas de Campos. (Re)Pensando a Educação Ambiental. In: TOZONI-REIS, Marília Freitas de Campos. Metodologias aplicadas à Eucação Ambiental. 2 ed. Curitiba: IESDE Brasil S.A., 2008. p. 7-17.

TREIN, Eunice. A educação ambiental crítica: crítica de que? Revista Contemporânea de Educação, n. 14, ago/dez, 2012. 